\title{
An option pricing approach to optimal bidding in construction projects
}

\author{
João Adelino Ribeiro ${ }^{1}$ | Paulo J. Pereira ${ }^{2}$ | Elisio M. Brandão ${ }^{2}$
}

${ }^{1}$ Department of Economics and Management Sciences, Universidade Autónoma de Lisboa, Rua de Santa Marta, 47, 1169-023 Lisbon, Portugal

${ }^{2}$ School of Economics and Management, University of Porto, Rua Dr. Roberto Frias, 4200-464 Porto, Portugal

\section{Correspondence}

João Adelino Ribeiro, Universidade Autónoma de Lisboa, Department of Economics and Management Sciences, Rua de Santa Marta, 47, 1169-023 Lisbon, Portugal.

Email: jribeiro@ual.pt

\section{Funding information}

FCT - Fundação para a Ciência e Tecnologia, Grant/Award Number: PEst-OE/EGE/ UI4105/2014 and SFRH/BD/71447/2010
Reaching an optimal mark-up value in the context of construction projects' bidding competitions has been a research topic for more than 40 years. This paper aims to contribute to this debate by applying a real options approach. The proposed model has a pure theoretical nature and is based on a maximization problem, whose outcome is the optimal price, that is, the price that should be included in the bid proposal. The model is later extended to accommodate the existence of penalty costs if the selected bidder refuses to enter into contract. Results reached using a numerical example demonstrate that the optimal price is higher when penalty costs are considered.

\section{1 | INTRODUCTION}

Determining the optimal mark-up bid in the context of public and private bidding competitions in the construction industry has been a central topic of discussion in the relevant literature, because Friedman (1956) and Gates (1967) set the standards for future debate. By adopting a new and innovative approach, under a real options framework, we propose a theoretical model that allows managers to determine the optimal price, in line with the value maximization principle.

The model is based on the valuation of a specific real option that can only be exercised by the selected bidder. This fact entails that the value of the option must be weighted by the probability of winning the bid. The model's outcome is the result of a maximization problem that integrates these two components: (a) the value of the option to sign the contract and (b) the probability of winning the bid. This maximization problem determines that to the highest value of the option to sign the contract, weighted by the probability of winning the bid, corresponds the optimal price. Unlike all the previous models addressing this subject, our approach is sustained by the fact that each bidder possesses flexibility as of whether to sign the contract and, also, because the expected amount of constructions costs, which served as the basis to determine the bid price during the bid preparation stage, will most likely vary from the moment the bid proposal is closed and delivered to the client and the moment the client selects one of the bidders. In fact, the selected bidder does have the flexibility to accept or decline the invitation to sign the contract and, subsequently, to invest in executing the project. Hence, the model is based on a real options approach, where irreversibility and uncertainty concerning the expected amount of investment costs are present, and also considers the importance of flexibility in the context of investment decisions. We later extend the model to include the possible existence of penalty costs, that is, the costs borne by the selected bidder if he or she declines the invitation to sign the contract.

The vast majority of projects in the construction industry are awarded through what is known as "tender" or "bidding" processes (Christodoulou, 2010). A bidding process consists of a number of contractors ${ }^{1}$ competing to perform a particular project by submitting a sealed proposal until a certain date previously defined by the client. The most usual format of a bidding process is based on the rule that-all other things being equalthe contract will be granted to the competitor that submitted the lowest bid (Chapman, Ward, \& Bennell, 2000; Cheung, Wong, Fung, \& Coffey, 2008; Plebankiewicz, 2014), that is, the lowest price. Bearing this in mind, it is easy to conclude that the client's decision is very straightforward but the contractor's decision on what price to bid is more difficult to reach, certainly being one of the most difficult decisions construction managers have to face during the bid preparation stage.

The construction industry is known for featuring strong levels of price competitiveness (Chao \& Liu, 2007; Ngai, Drew, Lo, \& Skitmore, 